\title{
People, Policy and Place relaunch: a note from the Editors
}

People, Place and Policy, published since 2007 by the Centre for Regional, Economic and Social Research at Sheffield Hallam University, is being relaunched in 2020 with a new format and an augmented editorial board.

Published as an electronic journal free to all, People, Place and Policy has sought to speak to and promote dialogue between academics, policy-makers and practitioners. Reflecting this ambition, we are pleased to showcase our exciting new format in this issue in our efforts to disseminate ideas, comment and findings across a range of contemporary policy issues. The new format brings together a wider range of contributions, combining traditional peer reviewed research articles and book reviews, with shorter 'focus' articles reporting on new research findings or providing commentary on burning social issues, 'practice papers' written by policy makers and practitioners that provide accounts of their work, as well as a 'feature graphic' to convey key observations and trends. We feel that this wider range of content will servethe needsand interests of our diverse audience even better but will enable People, Policy and Place to remain a forum for informed and well-written research and commentary on social policy. 